\title{
PENETAPAN KADAR TIMBAL (Pb) PADA PANGAN JAJANAN ANAK SEKOLAH (PJAS) DI SEKOLAH DASAR CIBIRU
}

\section{DETERMINATION OF LEAD (Pb) IN FOOD OF SCHOOL CHILDREN (PJAS) AT CIBIRU ELEMENTARY SCHOOL}

\author{
Anne Yuliantini, Noneng, Vina Juliana \\ Sekolah Tinggi Farmasi Bandung \\ Jalan Soekarno Hatta No 754, Bandung \\ Email:anne.yuliantini@stfb.ac.id
}

Submitted : 10 Maret 2018

Reviewed : 13 Maret 2018

Accepted: 30 Maret 2018

\begin{abstract}
ABSTRAK
Pangan Jajanan Anak Sekolah (PJAS) sangat digemari oleh anak sekolah dengan keanekaragaman jenisnya. Akan tetapi, ada fenomena yang patut diwaspadai dari PJAS terutama yang dijual di pinggir jalan, yaitu tercemar logam berat timbal. Karena toksisitasnya, BPOM RI membatasi cemaran timbal yang ada dalam makanan ebesar 0, 25 bpj. Penelitian ini bertujuan untuk menentukan kadar logam berat timbal pada PJAS di salah satu sekolah dasar wilayah Cibiru Bandung yang berada tepat di pinggir jalan raya. Sampel didestruksi pada suhu $110-320{ }^{\circ} \mathrm{C}$, ditambahakan $\mathrm{HCl} 10 \mathrm{M}$ sebagai katalis dan digenapkan dengan $\mathrm{HNO}_{3} 0,1 \mathrm{M}$. Analisis dilakukan secara kualitatif menggunakan serbuk KI dan $\mathrm{Na}_{2} \mathrm{CO}_{3}$ menunjukan hasil negatif sedangkan analisis secara kuantitatif dilakukan dengan mengukur serapan sampel menggunakan spektrofotometri serapan atom (SSA) pada panjang gelombang $217 \mathrm{~nm}$. Berdasarkan hasil penelitian yang dilakukan, kelima sampel diketahui mengandung logam timbal dengan rentang kadar 1,4644 - 5,6934 bpj. Sampel PJAS yang di analisis memiliki kadar timbal yang melebihi batas persyaratan BPOM sehingga dapat berbahaya jika dikonsumsi dalam jangka waktu yang lama.
\end{abstract}

Kata kunci : Timbal, Spektrofotometer Serapan Atom, destruksi, PJAS

\begin{abstract}
Food Snack (PJAS) is very popular with school children with its diversity. However, there is a phenomenon that should be aware of PJAS especially sold on the roadside, which is polluted heavy metal lead. Due to its toxicity, BPOM RI limit the contamination of lead in the food by $0.25 \mathrm{ppm}$. This study aims to determine the level of heavy metal lead at PJAS in one of the elementary schools Cibiru in Bandung area which is right on the edge of the highway. The sample was destructed at $110-320{ }^{\circ} \mathrm{C}, 10 \mathrm{M} \mathrm{HCl}$ was added as catalyst and was accomplished with $0.1 \mathrm{M}$ HNO3. The analysis was conducted qualitatively using $\mathrm{KI}$ and $\mathrm{Na}_{2} \mathrm{CO}_{3}$ powder showing negative results while quantitative analysis was performed by measuring sample uptake using atomic absorption spectrophotometry ( SSA) at a wavelength of $217 \mathrm{~nm}$. Based on the results of research conducted, the five samples are known to contain lead metal with a range of levels of 1.4644 - 5.6934 bpj. The PJAS samples analyzed have lead levels that exceed the limit of BPOM requirements so that it can be harmful if consumed in the long term.
\end{abstract}

Keywords: Lead $(\mathrm{Pb})$, AAS, destruction, PJAS 


\section{PENDAHULUAN}

Anak-anak merupakan aset dan generasi penerus bangsa, dimana masa depan bangsa ditentukan oleh anak-anak dimasa ini. Untuk meningkatkan kualitas anak-anak, diperlukan asupan gizi dan nutrisi yang baik. Akan tetapi, pengontrolan makanan yang dikonsumsi anak-anak cukup sulit dilakukan, terutama ketika anak berada di luar rumah, seperti di sekolah.

PJAS (Pangan Jajanan Anak Sekolah) yang dijual di sekitar sekolah terutama yang dijajakan di pinggir jalan sangat rentan terkena kontaminan, terutama logam berat timbal $(\mathrm{Pb})$. Sumber kontaminasi timbal dapat berasal dari bahan bakar kendaraan bermotor, udara, air yang melewati pipa timbal ataupun dari bahan-bahan dan peralatan yang digunakan dalam proses pembuatan PJAS tersebut (Gustina, 2012).

PJAS yang terkontaminasi timbal dan dimakan oleh anak-anak akan menyebabkan masalah kesehatan yang serius, diantaranya adalah anak dapat mengalami gejala anemia, hambatan dalam pertumbuhan, perkembangan kognitif yang buruk, sistem kekebalan tubuh melemah disertai gejala autis, bahkan dapat terjadi kematian dini (Yulaipi, 2013).

Menurut Peraturan Kepala BPOM RI Nomor HK.00.06.1.52.4011 tentang Penetapan Batas Maksimum Cemaran Dalam Makanan tahun 2009, batas maksimum cemaran timbal $(\mathrm{Pb})$ dalam makanan adalah $0,25 \mathrm{ppm}$. Mengonsumsi makanan jajanan yang terkontaminasi timbal terutama melebihi batas yang telah ditentukan dan dilakukan secara terus menerus dapat berakibat fatal sebagaimana telah disebutkan diatas, terutama pada anak-anak yang masih dalam tahap pertumbuhan, bahkan dapat terjadi kematian dini. konsentrasi $1 \mu \mathrm{g} / \mathrm{m}^{3}$ timbal yang berada di udara, akan berdampak pada peningkatan kadar timbal dalam darah antara 2,5-5,3 $\mu \mathrm{g} / \mathrm{dl}$. Apabila telah terakumulasi hingga $10 \mu \mathrm{g} / \mathrm{dl}$ pada seorang anak, maka poin IQ-nya cenderung menurun 2,5 poin, bahkan bisa kehilangan sampai empat poin IQ pada usia tujuh tahun (Habrianti, 2013).

Berdasarkan latar belakang tersebut, maka penelitian ini dilakukan untuk menentukan kadar cemaran logam berat timbal $(\mathrm{Pb})$ pada PJAS di Sekolah Dasar Cibiru menggunakan instrumen Spektrofotometri Serapan Atom (SSA) guna mengetahui paparan terhadap logam berat timbal khususnya di area Sekolah Dasar Cibiru karena SD ini berada tepat di pinggir jalan yang sering dilalui oleh banyak kendaraan bermotor dan memiliki pedagang PJAS di pinggir jalan tersebut.

\section{METODE PENELITIAN}

\section{Alat dan Bahan}

Alat yang digunakan dalam penelitian ini adalah alat-alat gelas (Erlenmeyer, labu ukur, pipet tetes, pipet ukur, tabung reaksi, corong gelas, vial), mikro pipet, timbangan analitik, oven, cawan, spatel, Spektrofotometri Serapan Atom (SSA).

Bahan yang digunakan dalam penelitian ini diantaranya PJAS (Pangan Jajanan Anak Sekolah), $\mathrm{Pb}\left(\mathrm{NO}_{3}\right)_{2}, \mathrm{HNO}_{3} 0,1 \mathrm{M}, \mathrm{HNO}_{3} 0,5 \mathrm{M}, \mathrm{HCl} 10 \mathrm{M}$, serbuk $\mathrm{KI}, \mathrm{Na}_{2} \mathrm{CO}_{3}$, Aquabidest.

\section{Jalannya Penelitian \\ 1. Validasi Metode}

Validasi metode meliputi pengujian beberapa parameter, diantaranya, linieritas yang didapat dari kurva kalibrasi, batas deteksi dan kuantisasi yang dihitung secara statistika dari persamaan kurva kalibrasi, presisi yang diukur dari nilai standar baku residual, dan akurasi yang diukur dari persen perolehan kembali.

\section{Pemilihan Sampel}

Sampel yang digunakan adalah pangan jajanan anak sekolah (PJAS). PJAS yang digunakan adalah PJAS yang dijajakan di pinggir jalan disekitar salah satu Sekolah Dasar di wilayah Cibiru kota Bandung. 


\section{Pembuatan larutan uji}

Sampel dipotong ukuran kecil-kecil dan dimasukkan ke cawan kosong yang akan digunakan untuk destruksi sampel. Sampel dikeringkan menggunakan oven pada suhu $110-320{ }^{\circ} \mathrm{C}$ selama 3 jam.Kemudian, cawan didinginkan dengan dimasukan ke dalam desikator dan ditimbang sehingga diperoleh bobot kering sampel.

Sampel ditumbuk hingga menjadi abu, ditambahkan $\mathrm{HCl} 10 \mathrm{M}$ kurang lebih $10 \mathrm{~mL}$ dan diaduk. Sampel dipanaskan di atas hot plate hingga mengering dan ditambahkan $\mathrm{HNO}_{3} 0,1$ $\mathrm{M}$, dimasukkan ke dalam labu ukur $100 \mathrm{~mL}$ dan digenapkan dengan $\mathrm{HNO}_{3}$ 0,1 $\mathrm{M}$, disaring menggunakan kertas saring dan dimasukan ke dalam botol.

\section{Uji Kualitatif}

\section{Pengujian I}

5,0 ml sampel dimasukkan ke dalam tabung reaksi, ditambah serbuk KI akan terbentuk endapan kuning.

\section{Pengujian II}

5,0 ml sampel dimasukkan ke dalam tabung reaksi, ditambah serbuk $\mathrm{Na}_{2} \mathrm{CO}_{3}$ akan terbentuk endapan putih.

\section{Penentuan Kadar Timbal Dalam Sampel}

Pengukuran sampel dilakukan setelah pembuatan kurva kalibrasi dari larutan timbal dengan konsentrasi 0,$1 ; 0,2 ; 0,3 ; 0,4 ; 0,5$ dan 0,6 bpj dalam larutan asam nitrat $0,5 \mathrm{M} \mathrm{v} / \mathrm{v}$. Serapan sampel yang diperoleh dimasukan kedalam persamaan kurva kalibrasi untuk memperoleh konsentrasi timbal dalam sampel yang dapat dikonversi dan diketahui kadarnya. Pengukuran dilakukan dengan menggunakan spektrofotometer serapan atom pada panjang gelombang $217 \mathrm{~nm}$.

Kadar timbal dapat dihitung dengan persamaan :

$\operatorname{Kadar}(\mathrm{mg} / \mathrm{kg})=\frac{\text { konsentrasi }\left(\frac{\mu g}{m L}\right) x \text { volume }(m L)}{\text { berat sampel }(g)}$

\section{HASIL DAN PEMBAHASAN}

Penetapan kadar timbal $(\mathrm{Pb})$ pada PJAS dilakukan menggunakan instrumen Spektrofotometer Serapan Atom karena waktu pengerjaan yang cepat, sensitif dan sangat spesifik untuk unsur yang akan di analisis (Dewi,2011). Tahapan-tahapan yang dilakukan dalam penetapan kadar logam timbal $(\mathrm{Pb})$ pada PJAS dimulai dengan pembuatan kurva kalibrasi, validasi metode analisis, destruksi sampel, dan penetapan konsentrasi logam timbal $(\mathrm{Pb})$ pada sampel secara kualitatif menggunakan pereaksi kimia dan kuantitatif menggunakan instrumen spektrofotometer serapan atom.

Validasi metode analisis dilakukan untuk membuktikan bahwa metode yang digunakan dalam penelitian ini memenuhi persyaratan sehingga dapat dinyatakan bahwa data yang diperoleh selama penelitian merupakan hasil yang baik dan dapat dipercaya. Uji linieritas suatu metode bertujuan untuk membuktikan adanya hubungan yang linier antara konsentrasi analit yang sebenarnya dengan respon alat. 


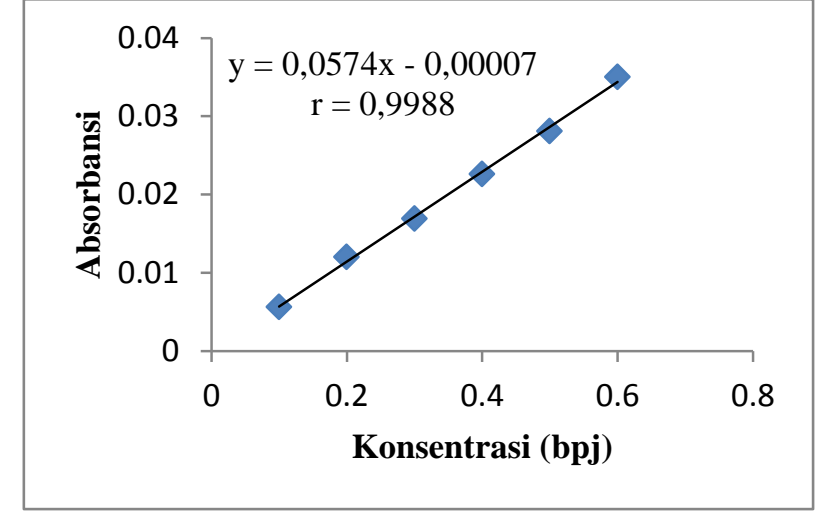

\section{Gambar 1. Kurva kalibrasi timbal}

Kelinearitasan dilakukan dengan memperhatikan faktor-faktor kelinearan garis seperti nilai koefisien korelasi (r), koefisien determinasi $\left(\mathrm{R}^{2}\right)$, dan nilai $\mathrm{Vx} 0$. Dari hasil pengukuran, diperoleh persamaan garis kurva kalibrasi timbal adalah $\mathrm{Y}=0,0574 \mathrm{x}-0,00007$ dengan koefisien korelasi (r) sebesar 0,9988. Hasil koefisien korelasi yang diperoleh dikatakan memenuhi syarat karena mendekati nilai 1 . Nilai koefisien determinasi $\left(\mathrm{R}^{2}\right)$ yang diperoleh adalah 0,998 .

Tabel II. Nilai BD dan BK

\begin{tabular}{|c|c|c|c|}
\hline $\begin{array}{c}\text { Kons } \\
(\mathbf{x})\end{array}$ & $\begin{array}{c}\text { Abs } \\
(\mathbf{y})\end{array}$ & $\frac{\mathbf{y}^{\prime}}{(\mathbf{b x}+\mathbf{a})}$ & $\left(y-y^{\prime}\right)^{2}$ \\
\hline $\begin{array}{c}0,1 \\
0,2 \\
0,3 \\
0,4 \\
0,5 \\
0,6 \\
\mathrm{Xi}=0,35 \\
\end{array}$ & $\begin{array}{c}0,0056 \\
0,012 \\
0,0169 \\
0,0226 \\
0,0281 \\
0,035\end{array}$ & $\begin{array}{l}0,00567 \\
0,01141 \\
0,01715 \\
0,02289 \\
0,02863 \\
0,03437\end{array}$ & $\begin{array}{c}4,9 \mathrm{E}-09 \\
3,481 \mathrm{E}-07 \\
6,25 \mathrm{E}-08 \\
8,41 \mathrm{E}-08 \\
2,809 \mathrm{E}-07 \\
3,969 \mathrm{E}-07 \\
\sum=1,1774 \mathrm{E}-06 \\
\end{array}$ \\
\hline Sy & $\mathrm{BD}$ & BK & Vx0 \\
\hline 0,000542 & 0,028355 & 0,094519 & $0,009451 \quad 2,7$ \\
\hline
\end{tabular}

Faktor kelinearitasan lainnya adalah Sx0 yaitu standar deviasi dari fungsi dengan nilai 0,009 dan koefisien korelasi dari fungsi ( $\mathrm{Vx} 0)$ merupakan koefisien yang menentukan nilai linearitas suatu persamaan. Untuk nilai $\mathrm{Vx} 0$ diperoleh hasil 2,7\%, nilai ini tidak memenuhi syarat kelinearan garis yaitu $\leq 2 \%$, hasilnya dapat dilihat pada tabel II.

Untuk akurasi atau kecermatan dinyatakan dalam uji perolehan kembali atau \%recovery. Presisi atau keseksamaan dinyatakan sebagai simpangan baku relatif (SBR). Akurasi dan presisi dilakukan pada 3 konsentrasi berbeda, yaitu konsentrasi $80 \%$; 100\%, dan $120 \%$, yaitu konsentrasi $0,2 \mathrm{ppm}$; 0,25 ppm; dan 0,3 ppm, dilakukan sebanyak 3 kali pengukuran selama 2 hari (intraday dan interday). 
Tabel III. Nilai rata-rata Presisi dan Akurasi Intraday

\begin{tabular}{ccc}
\hline $\begin{array}{c}\text { Konsentrasi } \\
(\%)\end{array}$ & Perolehan kembali & $\%$ \\
\hline 80 & 105,1394 & 1,435004 \\
100 & 99,44251 & 0,700770 \\
120 & 103,0004 & 0,651024 \\
\hline
\end{tabular}

Nilai SBR hari pertama untuk masing-masing konsentrasi yaitu $1,4 \% ; 0,7 \%$; dan $0,6 \%$, sedangkan nilai SBR pada hari ke dua untuk masing-masing konsentrasi adalah 0,9\%; 0,7\%, dan $0,6 \%$. Nilai-nilai ini memenuhi syarat karena $\leq 2 \%$.

Tabel IV. Nilai rata-rata Presisi dan Akurasi Interday

\begin{tabular}{ccc}
\hline $\begin{array}{c}\text { Konsentrasi } \\
(\%)\end{array}$ & $\begin{array}{c}\% \\
\text { Perolehan } \\
\text { kembali }\end{array}$ & $\begin{array}{c}\% \\
\text { SBR }\end{array}$ \\
\hline 80 & 101,9454 & 0,986642 \\
100 & 97,3519 & 0,715819 \\
120 & 101,6453 & 0,659703 \\
\hline
\end{tabular}

Rentang \% perolehan kembali pada hari pertama yaitu 99,44 - 105,13\%, sedangkan pada hari kedua rantangnya adalah $97,35-101,94 \%$. Hasil ini dikatakan memenuhi syarat, yaitu masih berada pada rentang $80-120 \%$.

Salah satu syarat analisis logam dengan menggunakan AAS adalah sampel harus berupa larutan, maka sebelum kadar $\mathrm{Pb}$ dalam PJAS dianalisis, dilakukan destruksi terlebih dahulu. Fungsi dari destruksi adalah untuk memutus ikatan antara senyawa organik dengan logam yang akan dianalisis. Dalam penelitian ini destruksi sampel dilakukan dengan metode destruksi kering, pemilihan destruksi didasarkan dari banyaknya kandungan senyawa organik dan anorganik di dalam sampel.

Proses destruksi kering dimulai dengan memanaskan sampel di dalam oven pada suhu $100^{\circ} \mathrm{C}$ dan $320^{\circ} \mathrm{C}$ selama 1 dan 2 jam. Penambahan masing-masing asam setelah sampel di panaskan menggunakan oven sampai menjadi abu mempunyai tujuan tersendiri. Asam pertama yang ditambahkan ke dalam sampel adalah $\mathrm{HNO}_{3} 0,1 \mathrm{M}$, fungsinya sebagai agen pengoksidasi utama karena $\mathrm{HNO}_{3} 0,1 \mathrm{M}$ merupakan pelarut logam yang baik, $\mathrm{Pb}$ dalam sampel teroksidasi oleh $\mathrm{HNO}_{3}$ 0,1 M sehingga menjadi larut. Asam kedua yang ditambahkan adalah $\mathrm{HCl} 10 \mathrm{M}$, fungsi penambahan $\mathrm{HCl} 10 \mathrm{M}$ adalah sebagai katalisator untuk mempercepat reaksi pemutusan ikatan logam timbal dengan senyawa organik yang ada dalam sampel PJAS.

Hasil uji kualitatif : (1) Positif $\mathrm{Pb}$ dengan menggunakan pereaksi serbuk KI. (2) Positif $\mathrm{Pb}$ dengan menggunakan pereaksi serbuk $\mathrm{Na}_{2} \mathrm{CO}_{3}$. 
Tabel V. Uji kualitatif

\begin{tabular}{ccc}
\hline Sampel & $\begin{array}{c}\text { Uji 1 } \\
(+\mathbf{K I})\end{array}$ & $\begin{array}{c}\text { Uji 2 } \\
\left(+\mathbf{N a}_{2} \mathbf{C O}_{3}\right)\end{array}$ \\
\hline 1 & + & + \\
2 & + & + \\
3 & + & + \\
4 & + & + \\
5 & + & + \\
\hline
\end{tabular}

Berdasarkan hasil pengujian kualitatif di atas, maka sampel dinyatakan positif mengandung $\mathrm{Pb}$, sehingga dilanjutkan ke pengujian kuantitatif menggunakan spektrofotometri serapan atom pada panjang gelombang $217 \mathrm{~nm}$ untuk mengetahui kadar logam timbal dalam masingmasing sampel tersebut.

Tabel VI. Kadar Timbal (Pb) dalam sampel

\begin{tabular}{ccc}
\hline Sampel & $\begin{array}{c}\text { Kadar } \\
(\mathrm{bpj})\end{array}$ & $\begin{array}{c}\text { Batasan } \\
(\mathrm{bpj})\end{array}$ \\
\hline 1 & 3,6621 & 0,25 \\
2 & 3,3769 & 0,25 \\
3 & 3,2635 & 0,25 \\
4 & 5,6934 & 0,25 \\
5 & 1,4644 & 0,25 \\
\hline
\end{tabular}

Dari kelima sampel PJAS yang dianalisis, ditemukan kadar timbal $(\mathrm{Pb})$ yang melebihi batas maksimum yang ditetapkan oleh Kepala BPOM RI Nomor HK.00.06.1.52.4011 tentang Penetapan Batas Maksimum Cemaran Dalam Makanan tahun 2009, batas maksimum cemaran timbal $(\mathrm{Pb})$ dalam makanan adalah 0,25 bpj.

Adanya timbal dalam PJAS dan dikonsumsi oleh anak-anak dalam jumlah yang berlebihan dapat menyebabkan masalah kesehatan, diantaranya keracunan, mengalami gejala anemia, hambatan dalam pertumbuhan, perkembangan kognitif yang buruk, sistem kekebalan tubuh melemah disertai gejala autis, bahkan dapat terjadi kematian dini (Habrianti, 2013).

Terdeteksinya logam timbal $(\mathrm{Pb})$ dalam sampel PJAS dapat dikatakan sebagai kontaminan karena logam ini berbahaya bagi tubuh. Logam timbal terdapat dalam sampel bisa karena sampel PJAS yang dijajakan tidak ditutup dengan benar sehingga terkontaminasi logam timbal yang terbawa oleh udara ataupun akibat akibat bahan baku yang digunakan dan penggunaan peralatan dalam membuat PJAS yang kurang memperhatikan aspek kebersihan.

\section{KESIMPULAN}

Sampel PJAS yang dianalisis memiliki kadar timbal 1,4644 - 5,6934 bpj, melebihi batas aman yang telah dipersyaratkan BPOM, yaitu $0,25 \mathrm{bpj}$, sehingga perlu dipertimbangkan untuk dikonsumsi dalam jangka waktu yag panjang.

\section{DAFTAR PUSTAKA}

Al Anshori, J. 2005. Spektrometri Serapan Atom. Fakultas matematika dan ilmu pengetahuan alam. Universitas Padjajaran. Bandung. 
Amin, M. 2015. Penentuan logam timbal (Pb)dalam minuman ringan berkarbonasi menggunakan destruksi basah secara spektroskopi serapan atom. Skripsi, Fakultas Sains dan Teknologi : Universitas Islam Negeri Maulana Malik Ibrahim Malang.

Badan Pengawasan Obat dan Makanan RI. 2006. Pedoman Kriteria Cemaran Pada Pangan Siap Saji Dan Pangan Industri Rumah Tangga.

Badan Pengawas Obat dan Makanan Republik Indonesia. 2007. Jajanan Anak sekolah. Sistem Keamanan Pangan Terpadu.

Direktorat Bina Gizi Ditjen Bina Gizi Dan Kesehatan Ibu Dan Anak Kementerian Kesehatan RI. 2011. Pedoman Keamanan Pangan di Sekolah Dasar. Jakarta.

Gandjar, G dan Rohman, A. 2007. Kimia Farmasi Analisis. Yogyakarta : Pustaka Pelajar.

Gustina, D. 2012. Pencemaran logam berat timbal (pb) di udara dan upaya penghapusan bensin bertimbal. Peneliti Bidang Komposisi Atmosfer, LAPAN.

Habrianti, D., Birawida, Bintara, A., dan Anwar. 2013. Konsentrasi logam berat timbal (pb) dalam makanan jajanan, kerang Anadara sp. dan urine siswa SD Negeri Tallo Tua 69 Makassar. Skripsi, Bagian Kesehatan Lingkungan Fakultas Kesehatan Masyarakat : Universitas Hasanudin, Makasar.

Hidayati, E. N., Alauhdin, M dan Prasetya, A.T. 2014. Perbandingan metode destruksi pada analisis pb dalam rambut dengan AAS, Indonesian Journal of Chemical Science 3 (1).

Kementerian Kesehatan RI. 2011. Pangan Jajanan Anak Sekolah (PJAS). Jejaring Informasi Pangan dan Gizi. 27(2):4.

Kepala Badan Pengawas Obat dan Makanan Republik Indonesia. Nomor HK.00.06.1.52.4011 tahun 2009 tentang penetapan batas maksimum cemaran mikroba dan kimia dalam makanan.

Menteri Kesehatan RI. 2003. Keputusan Menteri Kesehatan RI nomor 942/Menkes/Sk/VII/2003 Tentang Pedoman Persyaratan Hygiene Sanitasi Makanan Jajanan. Jakarta.

Raimon.1993. Perbandingan metode destruksi basah dan kering secara spektrofotometri serapan atom. Lokakarya Nasional. Jaringan kerjasama kimia analitik Indonesia. Yogyakarta.

Setiawan, H. 2013. Akumulasi dan distribusi pada vegetasi mangrove di perairan pesisir Sulawesi Selatan. Balai penelitian kehutanan Makasar.

Standar Nasional Indonesia. 2009. Batas maksimum cemaran logam berat dalam makanan. Nomor $7387: 2009$.

Triasari, R. 2015. Hubungan pengetahuan dan sikap mengenai jajanan yang aman dan perilaku memilih jajanan pada siswa kelasV SD Negeri Cipayung 2 kota Depok. Skripsi, Fakultas Kedokteran dan Ilmu Kesehatan : Universitas Islam Negeri Syarif Hidayatullah : Jakarta.

Yulaipi, S., dan Aunurohim. 2013. Bioakumulasi Logam Berat Timbal (Pb) dan Hubungannya dengan Laju Pertumbuhan Ikan Mujair (Oreochromis mossambicus. Jurnal sains dan seni pomits vol. 2, no.2. 